\title{
METHADONE AND CANCER PAIN: A REFLEX(ION) OF A PALLIATIVE CARE SERVICE
}

$16^{\text {th }}$ World Congress of the

European Association for Palliative Care

\section{Susete Freitas Md, Ferraz Gonçalves PhD}

Palliative Care Unit of Portuguese Institute Of Oncology of Porto, Porto, Portugal

\section{INTRODUCTION}

The treatment of pain constitutes one of the main goals of palliative care in patients with advanced cancer Although methadone is used for the treatment of chronic pain, as an e ff e c ti $v$ e a $n d$ inexpensive strong opioid, is less used in many pain and palliative services due to its unpredictable half-life and potential toxicity.

\section{AJM}

The purpose of this work was to describe the prescription and outcomes of methadone as a second-line treatment for refractory cancer pain to "classic" opioids in a tertiary palliative care unit

\section{METHODS}

Retrospective review, for a six-year period, of medical patients records, from an oncologic palliative care service, described with cancer pain undergoing treatment with oral methadone. Data collected include disease and pain characteristics, initial opioid type, doses and outcomes in the Palliative Care Unit of the Portuguese Institute of Oncology of Porto, Portugal.
RESULTS Were identified 58 patients treated with methadone at PCU. However 39 clinical processes were excluded: 30 due to lack of information and 9 already on Methadone for addiction rehab programe

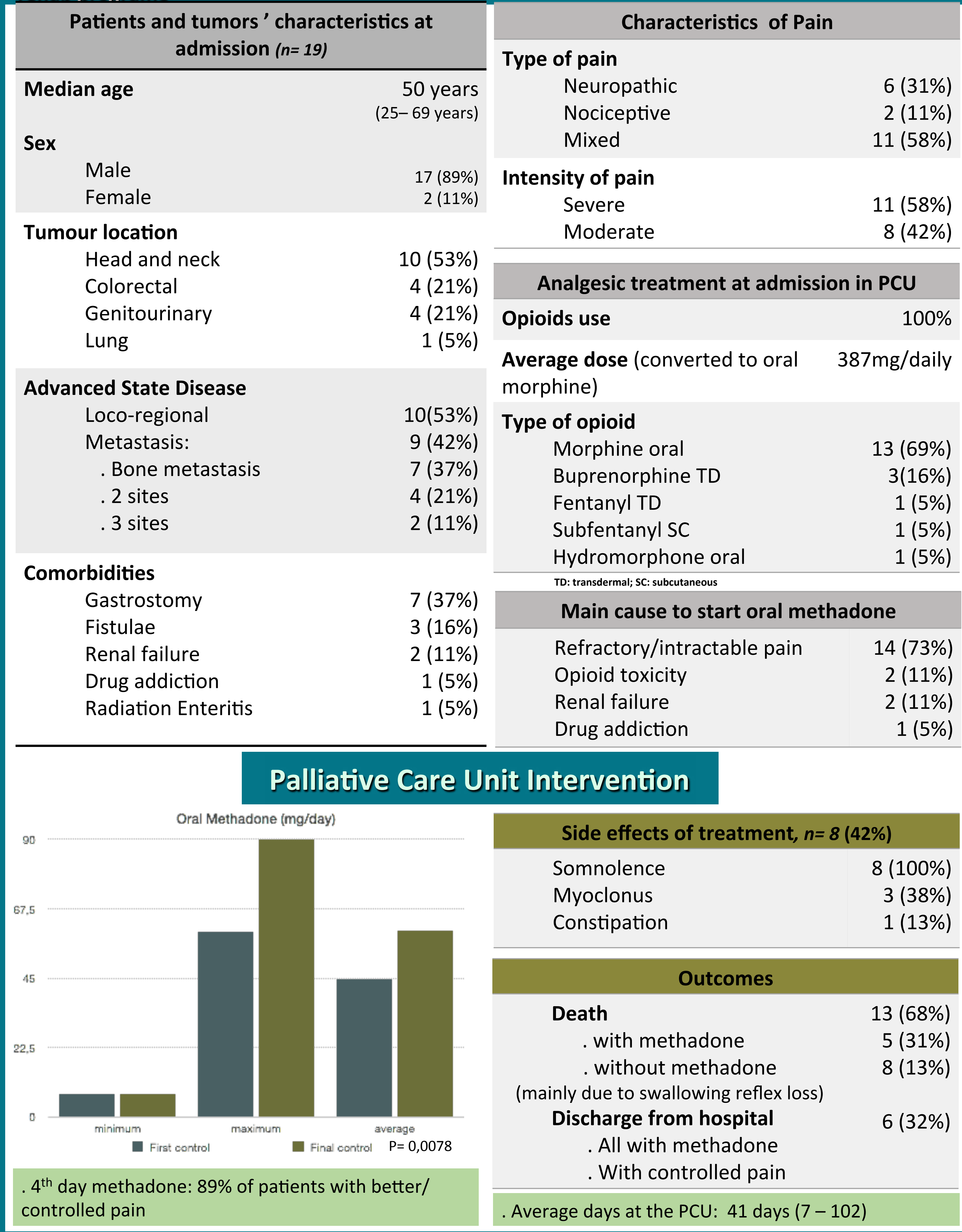

\section{CONCLUSION}

The refractory pain with "classic" opioids could be common in palliative care services due the high prevalence of complexity of these patients. Methadone is an eligible opioid to treat cancer pain, about mostly in experienced teams, providing good pain control with poor side effects. 